\title{
Influence of Using Coconut, Palm, and Corn Oils as Frying Medium on Concentration of Acrylamide in Fried Tempe
}

\author{
M. Muchtaridi", J. levita, D. Rahayu, H. Rahmi \\ Division of Pharmacochemistry, Faculty of Pharmacy, Universitas Padjadjaran, J1 KM 21.5 Bandung-Sumedang, Jatinangor, Indonesia
}

\begin{abstract}
The aim of this research is to study the formation of acrylamide with different kind of vegetable oils as the cooking media. The samples were prepared by cooking and baking above $120^{\circ} \mathrm{C}$ then extracted with dichloromethane-ethanol and separated by SPE (C-18) with methanol $60 \%$ as eluent. The extracts were analysed by HPLC, with condition as followed: C-18 column; acetonitrile-water (5:95) pH 2.52 mobile-phase; $0.5 \mathrm{ml} /$ minute flow rate; and $210 \mathrm{~nm}$ wavelength. It was figured out that a fried tempe using corn oil contained $0.5778 \mu \mathrm{g} / \mathrm{g}$ acrylamide $(8.202 .10-3$ standard deviation and $1.4195 \%$ coefficient variation), using coconut oil $0.192 \mu \mathrm{g} / \mathrm{g}$ acrylamide (5.656.10-3 standard deviation $2.946 \%$ coefficient variation), using palm oil $0.1455 \mu \mathrm{g} / \mathrm{g}$ acrylamide (6.081.10-3 standard deviation and $4.1794 \%$ coefficient variation).
\end{abstract}

Keywords acrylamide, tempe, coconut oil, palm oil, corn oil

\section{Introduction}

The Swedish National Food Authority and the University of Stockholm have conducted valuable research in the field of food safety in April 2002[1]. These researchers found microgram per kilogram to milligram per kilogram levels of acrylamide in foods[2]. Acrylamide is a reactive chemical, which is used as monomer in the synthesis of polyacrylamides used in purification of water, and in the formulation of grouting agents. Acrylamide is known as a component in tobacco smoke.

The International Agency for Research on Cancer (IARC) has classified acrylamide as probably carcinogenic to humans (Group 2A). Neurological effects have been observed in humans exposed to acrylamide. Properties, use and toxic effects of acrylamide are reviewed by IARC and EU[3].

Several sources of hypothesis for the formation of acrolein are known[4]. It may arise from degradation of amino acids from proteins and degradation of carbohydrates, and also from the Maillard reaction between amino acids or proteins and carbohydrates[5,6]. Glycerol is degraded to acrolein[6], the unpleasant acrid black and irritating smoke, when oil is heated at tempe fried temperatures above the smoke point $\left(260-290^{\circ}\right)$. The smoke point is higher for oils with higher content of saturated fatty acids and lower content of polyun-

* Corresponding author:

muchtaridi@unpad.ac.id (M. Muchtaridi)

Published online at http://journal.sapub.org/fph

Copyright (C) 2012 Scientific \& Academic Publishing. All Rights Reserved saturated acids. The smoke points for some of the main oils and fats are as follows: palm ${ }^{\circ} \mathrm{C}$, peanut $220^{\circ} \mathrm{C}$, olive: $210^{\circ} \mathrm{C}$, lard and copra $180^{\circ} \mathrm{C}$, sunflower and soybean $170^{\circ} \mathrm{C}$, corn $160^{\circ} \mathrm{C}$, margarine $150^{\circ} \mathrm{C}$, and butter $110^{\circ} \mathrm{C}[4,7-9]$. Usually, the smoke starts to appear on the surface of heated oils before their tempe reaches $175^{\circ} \mathrm{C}$. The oil is first hydrolyzed into glycerol and fatty acids and then acrolein is produced by the elimination of water from glycerol by a heterolytic acidcatalyzed carbonium ion mechanism followed by oxidation[2].

$$
\mathrm{CH} 2(\mathrm{OH})-\mathrm{CH}(\mathrm{OH})-\mathrm{CH} 2(\mathrm{OH}) \rightarrow \mathrm{CH} 2=\mathrm{CH}-\mathrm{CHO}
$$$$
\text { Glycerol Acrolein }
$$

Acrolein can be converted into acrylamide by a series of fundamental reactions. However, both acrolein and acrylamide are reactive, because of their double bonds and the amino group of acrylamide. They can readily react further with other reactive groups present in the food matrix or formed during the heating process. For example, acrylamide can react with small reactive molecules, such as urea $(\mathrm{CO}(\mathrm{NH} 2) 2)$ and formaldehyde $(\mathrm{HCHO})$, or with glyoxal ((CHO)2), aldehydes (RCHO), amines (R2NH), thiols (RSH) etc. Furthermore, the products shown in the following scheme can even react further in the same mode of reaction[2].

The study of acrylamide formation has been published in many paper, even potato fried study is investigated comprehensively[10,11]. However, the study of formation acrylamide in tempe has not yet been fully investigated, for the reason that tempe are consumed almost daily in Indonesia[12]. The objective of this research would be proofed of 
the influence of usage of coconut oil (with $84 \%$ trygliseride), palm oil (with $84 \%$ trygliseride) and corn oil (with $98.4 \%$ trygliseride) as frying media to content of acrylamide at tempe.

\section{Materials and Methods}

\subsection{Materials}

Chemicals. The following chemicals were obtained commercially: acrylamide pro analysis $(99 \%$, Merck), dichloromethane (Merck), ethanol and methanol grade HPLC (Merck), acetonitrile grade HPLC (Merck), phosphoric acid grade HPLC (Merck), Cartridge C-18 for SPE (Solid Phase Extraction) from Waters, Aquabidest pro injection (Ikapharmindo), $\mathrm{KBr}$ p.a (Merck).coconut oils, palm oils, corn oil, and tempe were obtained from a local grocery store.

Instrument. HPLC: LC 10A-UV-vis SPD-10AV (Schimadzu), Vortex mixer 300, Ultrasonic shaker (NEY), Laboratory Shaker (IKA-HS 260), Spectrometry (Jena Specord 200), and $\mathrm{pH}$ meter.

\subsection{Methods}

\section{Sample Preparation}

Tempe was taken from Cileunyi Traditional Market in February 2006.

The methods and procedure was adapted from Harahap et al.[13]. Tempe was fried until smoke point temperature by three frying media (coconut oils (sample A), palm oils (sample B), and corn oils (sample C)). The output of this process was called samples. 15 gram of samples were weighed, then it was dissolved in $60 \mathrm{~mL}$ dichloromethane and $3 \mathrm{ml}$ ethanol $\mathrm{ml}$, last be shacked with shaker laboratory at a speed at $210 \mathrm{rpm}$ during 50 minute. The solution was filtered and filtrate was dissociated. The residue was cleaned by $20 \mathrm{~mL}$ dichloromethane, and then filtered. Into filtrate added $30 \mathrm{ml}$ mobile phase, and it was evaporated in at $700^{\circ} \mathrm{C}$, furthermore be packed into centrifugation tube at $8000 \mathrm{rpm}$ during 30 minute. The layer of mobile phase in centrifugation was taken into volumetric flask $25 \mathrm{ml}$ and added mobile phase until border. The solution in the volumetric flask was filtered with membrane filter ( 0.45 millipore $)$ and $20 \mu \mathrm{L}$ filtrate was injected into HPLC instrument. In this study, Solid Phase Extraction (C-18) was employed with methanol $60 \%$ as eluent for acrylamide extraction and clean-up[14,15]. Determination of Maximum Wave Length of Acrylamide

Standard solution of acrylamide was produced with dissolved $262 \mathrm{mg}$ acrylamide into $250 \mathrm{~mL}$ of mixture solution of mobile phase (acetonitrile: $\mathrm{H}_{2} \mathrm{O}(5: 95) \mathrm{pH}$ 2.52). This standard solution was diluted to obtain concentration of 4 $\mathrm{mg} / \mathrm{L}$. solution of $4 \mathrm{mg} / \mathrm{L}$ was determined by UV with range wave length 190-390 nm.

\section{Calibration Curve}

$10 \mathrm{mg} / \mathrm{L}$ of solution standard was diluted to obtain range concentration 2.032, 1.016, 0.813, 0.609, 0.508, 0.406, 0.203, and $0.102 \mathrm{mg} / \mathrm{L}$. The all concentration were performed by HPLC with detector UV in $198 \mathrm{~nm}$. Concentrations were plotted into area peak as shown in Fig. 1.

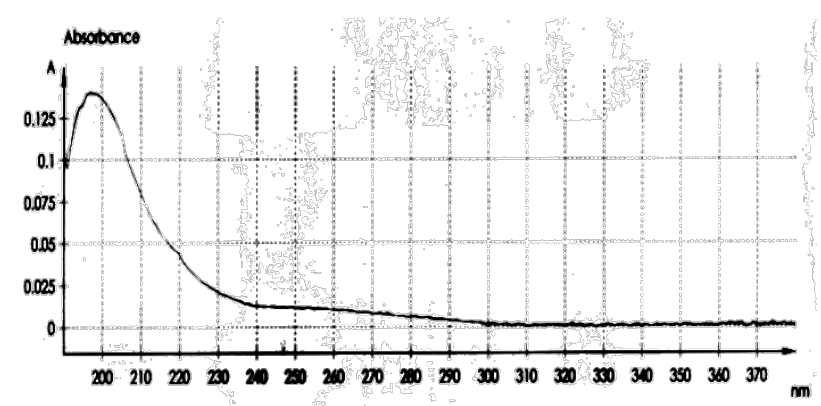

Figure 1. Maximum Absorbance of Acrylamide at concntration 0.508 $\mu \mathrm{g} / \mathrm{ml}$ by Using Spectrometre (UV-1700 Pharmaspec-Shimadzu)

\section{Repeatability Test}

$20 \mu \mathrm{l}$ standard solution $10 \mathrm{mg} / \mathrm{L}$ was injected into column by using mobile phase and condition as mention above. This experiment was repeated three times, thus calculated variation coefficient.

\section{Recovery Analysis}

$20 \mathrm{mg}$ acrylamide was added into 20 gram fried tempe and crushed homogeneity. After that, 2 gram was taken from the sample and dissolved in solvent dichloromethane: ethanol $(20: 1)$. The mixture was shaken by laboratory shaker (IKA HS 260) in 300 minutes. Sample was filtrated and added $100 \mathrm{mM}$ phosphoric acid.

\section{HPLC Analysis}

The methods analysis adapted from Sanders et al.[16] and Harahap et al.[13]. Samples were analyzed with a LC-10A (Schimadzu) interfaced to Detector UV-Vis SPD 10AV $(\lambda=$ $210 \mathrm{~nm}$ ). Column Lichro CART C-18 RP Select-B, $5 \mu \mathrm{m}$ id. $4 \mathrm{~mm}$. Mobile phase: Acetonitrile: $\mathrm{H} 2 \mathrm{O}$ (5:95), $10 \mathrm{mM}$ phosphoric acid, adjusted to $\mathrm{pH} 2.52$. Flow rate: $0.5 \mathrm{~mL} / \mathrm{min}$. $\mathrm{LC}$ mode injection: Direct (no split). Injection volume: $20 \mu \mathrm{L}$.

\section{Analysis of Data}

Response ratios area of acrylamide in sample peak/area of acrylamide standard peak was plotted against the corresponding concentration ratios for a series of five standards in dichloromethane. Standards contained concentrations ranging from 0 to $2 \mathrm{~g} / \mathrm{mL}(0.1,0.2,0.4,0.6,0.8,1.0$, and 2.0$)$. Linear regression resulted in a calibration curve from which concentration ratios in extracts were determined from measured response ratios.

\section{Results and Discussion}

\section{Validation of Analysis Methods}

Acrylamide had maximum absorbance on wave length $198 \mathrm{~nm}$ that calculated at concentration $0.508 \mu \mathrm{g} / \mathrm{ml}$ into dichloromethane as solvent as shown in Fig 1. This wave length was applied to evaluated sample in detector of HPLC.

The various methods for determination of acrylamide includes about the occurrence, analytical methods, and extraction and clean-up procedures of acrylamide has been established, however special attention is given to chromatographic techniques applied for the occurrence and determination of acrylamide[17]. Here we studied by using HPLC 
with addition standard methods. In this study, combination solvents was tried to get optimum analysis. The using of acetonitrile:water (5:95) in 10\% phosphoric acid gave optimum condition in analysis. As shown in Fig. 2, peak of acrylamide in chromatogram was clear at 7.30 minutes.

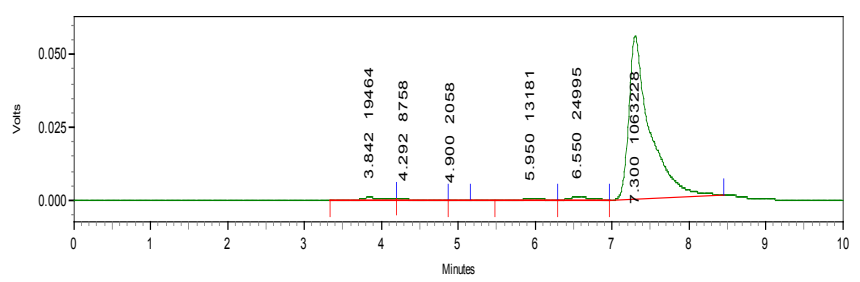

Figure 2. Chromatogram of Acrylamide use HPLC online UV detection with wave length $198 \mathrm{~nm}$ with mobile phase acetonitrile:water (5:95) and 10 $\mathrm{mM}$ phosphoric acid $\mathrm{pH} 2.52$

The equation of linear regression at curve calibrate which obtained from data processing of Table 1 was $y=218914 x+$ 1973.9 with quadrates relation coefficient $\mathrm{r} 20.99$. The calibration curve of acrylamide was presented in Fig. 3.

Table 1. Data of calibration curves of acrylamide standard

\begin{tabular}{ccc}
\hline Retention time (minutes) & Concentration $(\mathrm{ppm})$ & Peak Area \\
\hline 7.317 & 0.10 & 23625 \\
7.267 & 0.20 & 47372 \\
7.733 & 0.40 & 92647 \\
7.992 & 0.50 & 111997 \\
7.342 & 0.60 & 135251 \\
7.475 & 0.80 & 178659 \\
\hline
\end{tabular}

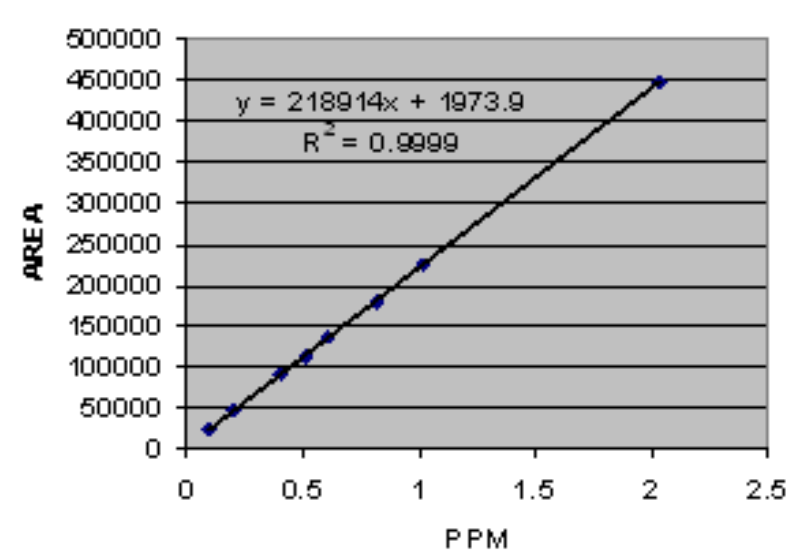

Figure 3. Calibration curve of Acrylamide Analysis by HPLC in wave length $198 \mathrm{~nm}$ with mobile phase acetonitrile:water (5:95) and $10 \mathrm{mM}$ phosphoric acid $\mathrm{pH} 2.52$

In addition, calibration curve which obtained from this research have homogeneously of good data and small deviation. The recoveries of acrylamide were presented as followed: $99.7217 \pm 1.2153 \%$ at concentration $0.1016 \mu \mathrm{g} / \mathrm{mL}$, $99.2439 \pm 1.8217 \%$ at concentration $0.508 \mu \mathrm{g} / \mathrm{mL} .100 .5914 \pm$ $3.0576 \%$ at concentration $1.016 \mu \mathrm{g} / \mathrm{mL}$.

LOD and LOQ of the method were obtained from calibration curve and the injection of mobile phase 8 times[18]. The calibration curve was obtained from eight concentrations of acrylamide standard solution within 0.1016-2.032 $\mu \mathrm{g} / \mathrm{mL}$ of range. The correlation coefficient $(r)$ was 0.9999 .
LOD that was obtained from the measurement of blank signal was $0.0125 \mu \mathrm{g} / \mathrm{mL}$ and the LOQ was $0.0398 \mu \mathrm{g} / \mathrm{mL}$.

\section{The level of acrylamide of sample}

The results of determined of acrylamide in sample can be seen in Table 2 and Fig. 1-3. In this research, the content of acrylamide in fried tempe with corn oil excess than content acrylamide in fried tempe with coconut oil and palm oil as frying medium. The averages level of acrylamide in fried tempe with coconut oils, palm oils, and corn oils as frying medium were $0.5778 \mu \mathrm{g} / \mathrm{g}$ (SD 8.202.10 $0^{-3}$ and coefficient variation $1.4195 \%$ ) $0.192 \mu \mathrm{g} / \mathrm{g}$ (SD 5.656.10 $0^{-3}$ and coefficient variation $2.946 \%$ ). and $0.1455 \mu \mathrm{g} / \mathrm{g}\left(\mathrm{SD} 6.081 .10^{-3}\right.$ and variation coefficient $4.1794 \%$ ), respectively. However, this content is far less than that found in French fries[10,15]. However, extraction process of acrylamide from crude sample of fried tempe play role in this analysis. Combining of dichloromethane and ethanol (20:1) was applied as solvent to attract acrylamide and then SPE with C-18 column was employed to isolate acrylamide in the mixture solution. This extraction method has been successfully to take acrylamide in the sample that indicated of recovery value in this analysis.

Table 2. Identification and Quantification of Acrylamide in Fried Tempe Using Different Oils

\begin{tabular}{ccccc}
\hline Sample & Replication & $\begin{array}{c}\text { Retention } \\
\text { Time } \\
(\text { minutes })\end{array}$ & $\begin{array}{c}\text { Concentration } \\
(\mu \mathrm{g} / \mathrm{g})\end{array}$ & $\begin{array}{c}\text { Coefficient } \\
\text { Variation }\end{array}$ \\
\hline In & 1 & 7.850 & 0.196 & \\
Coconut & 2 & 7.820 & 0.188 & \\
oils & 3 & 7.850 & 0.188 & $2.946 \%$ \\
Average & & & $0.1920 \pm$ & \\
& 1 & 7.933 & $5.7 .10^{-3}$ & \\
In Palm & 2 & 7.900 & 0.149 & \\
oils & 3 & 7.900 & 0141 & \\
& & & $0.1455 \pm$ & \\
Average & & & $4.08 .10^{-3}$ & \\
& 1 & 7.858 & 0.5720 & \\
In corn & 2 & 7.850 & 0.5610 & \\
oils & 3 & 7.850 & 0.5700 & $1.3730 \%$ \\
Average & & & $0.5665 \pm$ & \\
\hline
\end{tabular}

Effect of oil as a medium frying medium in the formation of acrylamide has been published by previous research[19, 20]. The difference of content of acrylamide at fried tempe by using these three oils as frying medium was estimated to be caused by the existence of difference of fat or fatty acid composition from third oils used.

In the corn oil, the content of fatty acid unsaturated is dominant and that is linoleic acid (56\%). On the other hand, it is predominated by trygliseride that is equal to $98 \%$. The formation of acrolein is known to increase with the increase in unsaturation in the oil and to lead to a lowering of the smoke point. The acrolein is higher for oils with higher content of trygliseride, because increasing of trygliseride in oils, increased content of glycerol that degraded to acrolein[1]. 


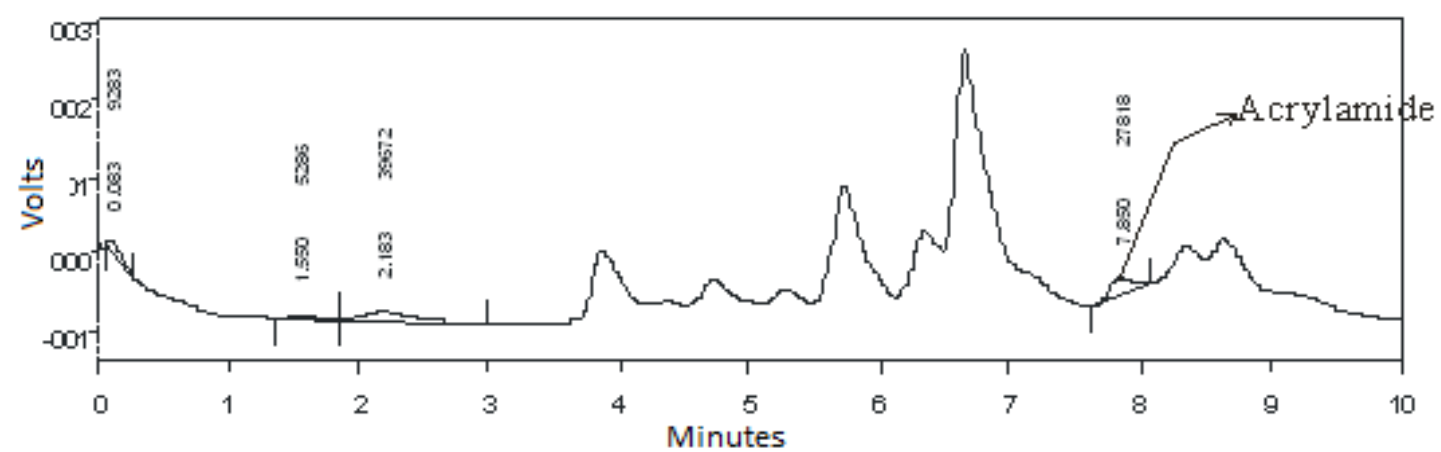

Figure 4. Chromatographic separation of the acrylamide in fried tempe with coconut oils as frying medium in wave length $198 \mathrm{~nm}$ with mobile phase acetonitrile:water (5:95) and $10 \mathrm{mM}$ phosphoric acid pH 2.52

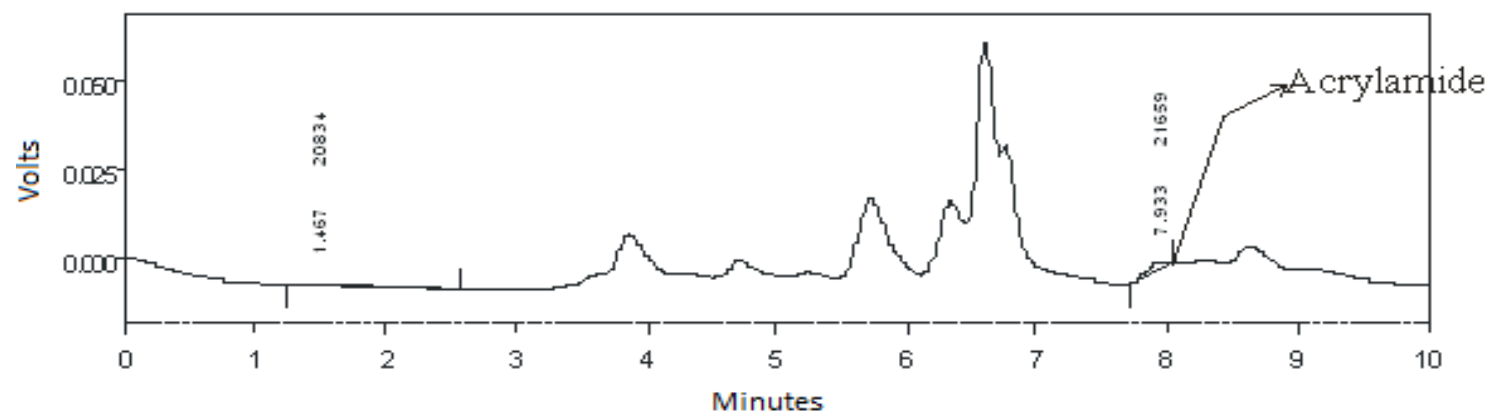

Figure 5. Chromatographic separation of the acrylamide in fried tempe with palm oils as frying medium in wave length $198 \mathrm{~nm}$ with mobile phase acetonitrile:water (5:95) and $10 \mathrm{mM}$ phosphoric acid $\mathrm{pH} 2.52$

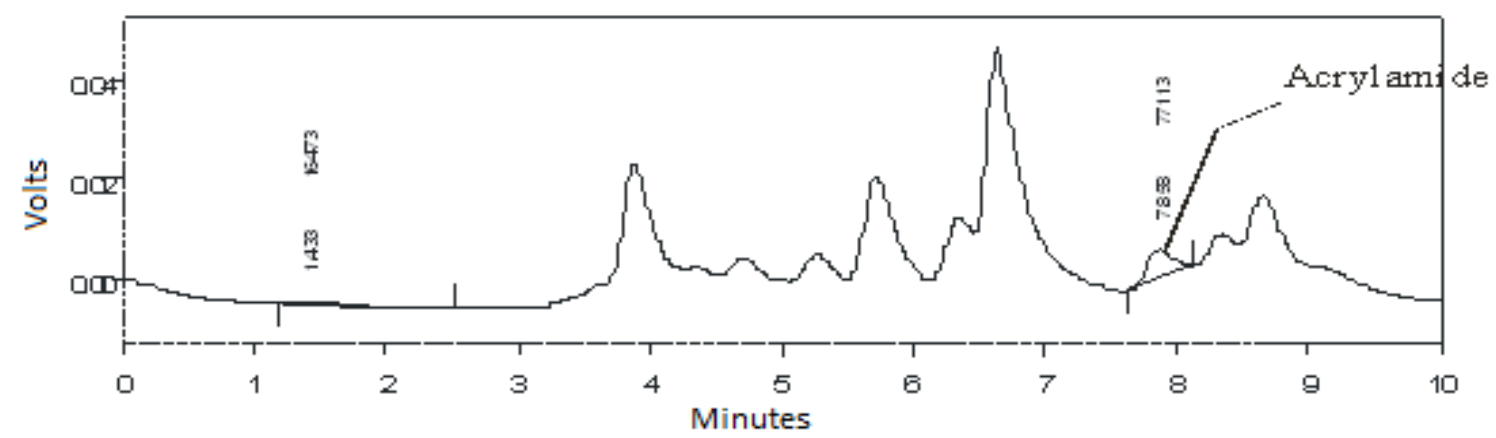

Figure 6. Chromatographic separation of the acrylamide in fried tempe with corn oils as frying medium in wave length $198 \mathrm{~nm}$ with mobile phase acetonitrile:water (5:95) and $10 \mathrm{mM}$ phosphoric acid $\mathrm{pH} 2.52$

\section{Conclusions}

In this study was known that found microgram per kilogram levels of acrylamide in fried tempe by using different oils as frying medium. The average level of acrylamide in fried tempe with coconut oils, palm oils, and corn oils as frying medium were $0.5778 \mu \mathrm{g} / \mathrm{g}\left( \pm 8.202 .10^{-3}\right.$ and coefficient variation $1.4195 \%) 0.192 \mu \mathrm{g} / \mathrm{g}\left( \pm 5.656 .10^{-3}\right.$ and coefficient variation $2.946 \%)$. and $0.1455 \mu \mathrm{g} / \mathrm{g}\left( \pm 6.081 .10^{-3}\right.$ and variation coefficient $4.1794 \%$ ). respectively.

\section{ACKNOWLEDGEMENTS}

We would gratefully acknowledge Indonesian Ministry of National education for funding this project through PHK A2project 2008 .

\section{REFERENCES}

[1] S. Grivas, et al., "Mechanisms of formation and influencing factors during heating of foods," The Swedish Institute for Food and Biotechnology2002.

[2] H. Lingnert, et al., "Acrylamide in food: mechanism of formation and influencing factors during heating of foods," App. Nutr. Food Chem. , vol. 46, pp. 159 - 172, 2002.

[3] IARC, "Monographs on the Evaluation of Carcinogen Risk to Humans: Some Industrial Chemicals," vol. 60, ed. Lyon: International Agency for Research on Cancer, 1994.

[4] E. Tareke, et al., "Analysis of acrylamide, a carcinogen formed in heated foodstuffs," J Agric Food Chem, vol. 50, pp. 4998-5006, Aug 142002.

[5] D. S. Mottram, et al., "Acrylamide is formed in the Maillard reaction," Nature, vol. 419, pp. 448-9, Oct 32002.

[6] R. A. Alarcon, "Formation of acrolein from various amino- 
acids and polyamines under degradation at 100 degrees C," Environ Res, vol. 12, pp. 317-26, Dec 1976.

[7] D. V. Zyzak, et al., "Acrylamide formation mechanism in heated foods," J Agric Food Chem, vol. 51, pp. 4782-7, Jul 30 2003.

[8] E. Choe and D. B. Min, "Chemistry of deep-fat frying oils," $J$ Food Sci, vol. 72, pp. R77-86, Jun 2007.

[9] D. Morgan, "Smoke, fire, and flash points of cottonseed, peanut, and other vegetable oils," Journal of the American Oil Chemists' Society, vol. 19, pp. 193-198, 1942.

[10] R. J. Foot, et al., "Acrylamide in fried and roasted potato products: a review on progress in mitigation," Food Addit Contam, vol. 24 Suppl 1, pp. 37-46, 2007.

[11] K. Grob, "Options for legal measures to reduce acrylamide contents in the most relevant foods," Food Addit Contam, vol. 24 Suppl 1, pp. 71-81, 2007.

[12] S. Handajani, "Indigenous mucuna tempe as functional food," Asia Pac J Clin Nutr, vol. 10, pp. 222-5, 2001.

[13] Y. Harahap and B. S. Harmita, "Optimization of the Determination of Acrylamide that Added to of potato chips in High-performance Liquid Chormatography Simulation," Majalah Ilmu Kefarmasian, vol. 1, pp. 154-163, 2005.
[14] T. Wenzl, et al., "Analytical methods for the determination of acrylamide in food products: a review," Food Addit Contam, vol. 20, pp. 885-902, Oct 2003.

[15] J. S. Ahn, et al., "Verification of the findings of acrylamide in heated foods," Food Addit Contam, vol. 19, pp. 1116-24, Dec 2002.

[16] R. A. Sanders, et al., "An LC/MS acrylamide method and its use in investigating the role of asparagine," in 116th Annual AOAC International Meeting, Los Angles, 2002.

[17] Y. Zhang and G. Zhang, "Occurrence and analytical methods of acrylamide in heat-treated foods. Review and recent developments," J Chromatogr A, vol. 1075, pp. 1-21, May 20 2005.

[18] S. Ibrahim, "Pengembangan Metode Analisis Menggunakan Kromatografi Cair Kinerja Tingg," presented at the Seminar on HPLC Application for Analysis of Drugs, Food, and Environtment, Bandung, 2001.

[19] F. J. Mestdagh, et al., "Influence of oil type on the amounts of acrylamide generated in a model system and in French fries," J Agric Food Chem, vol. 53, pp. 6170-4, Jul 272005.

[20] R. H. Stadler and G. Scholz, "Acrylamide: an update on current knowledge in analysis, levels in food, mechanisms of formation, and potential strategies of control," Nutr Rev, vol. 62, pp. 449-67, Dec 2004. 